\title{
Psychostimulant-Induced Fos Protein Expression in the Thalamic Paraventricular Nucleus
}

\author{
Ariel Y. Deutch, Michael Bubser, and Cheryl D. Young \\ Departments of Psychiatry and Pharmacology, and Center for Molecular Neuroscience, Vanderbilt University School of \\ Medicine, Nashville, Tennessee 37212
}

\begin{abstract}
Lesions of glutamatergic afferents to the nucleus accumbens have been reported to block psychostimulant-induced behavioral sensitization. However, thalamic glutamatergic projections to the nucleus accumbens have received little attention in the context of psychostimulant actions. We examined the effects of acute amphetamine and cocaine administration on expression of Fos protein in the thalamic paraventricular nucleus (PVT), which provides glutamatergic inputs to the nucleus accumbens and also receives dopaminergic afferents. Immunoblot and immunohistochemical studies revealed that both psychostimulants dose-dependently increased PVT Fos expression. PVT neurons retrogradely labeled from the nucleus accumbens were among the PVT cells that showed a Fos response to amphetamine. $D_{2}$ family dopamine agonists, including low doses of the
\end{abstract}

The nucleus accumbens (NAS) is a major site of psychostimulant drug actions (Di Chiara and Imperato, 1988; Kalivas and Stewart, 1991; Wise, 1996). In particular, the accumbal dopamine (DA) innervation appears critical for both the locomotor effects and rewarding properties of psychostimulants (Kalivas and Stewart, 1991; Wise, 1994; Robbins and Everitt, 1996). Converging data indicate that glutamatergic systems modulate striatal DA function and thereby regulate psychostimulant-induced locomotor behavior and sensitization (Kalivas, 1995; McGinty, 1995; Wolf, 1998). Among these data are reports showing that lesions of glutamatergic projections to the NAS, including those from the medial prefrontal cortex (PFC), amygdala, and hippocampus, alter psychostimulant-induced locomotor behavior and behavioral sensitization (Post et al., 1988; Yoshikawa et al., 1991; Burns et al., 1993; Wolf et al., 1995; Pierce et al., 1998).

The thalamus is a major source of glutamatergic projections to the striatal complex (Christie et al., 1987; Fuller et al., 1987). However, thalamostriatal projections have received scant attention in the context of psychostimulant actions. Because thalamic sites that project to the striatum are components of distinct cortico-striato-pallido-thalamic loops that have been suggested to cooperatively subserve certain psychostimulant actions (Deutch

Received Aug. 20, 1998; revised Sept. 25, 1998; accepted Sept. 30, 1998.

This work was supported in part by National Institute of Mental Health Grants MH-45124 and MH-57995 (A.Y.D.), the National Parkinson Foundation Center of Excellence at Vanderbilt University (A.Y.D.), and a National Alliance for Research on Schizophrenia and Depression Young Investigator Award (M.B.). We appreciate the expert technical assistance of Patricia Z. Gallipoli and are indebted to Dr. Michael Iadarola for the Fos antiserum. We acknowledge the qualms of one reviewer concerning the last sentence in this manuscript; we feel the topic should be experimentally addressed.

Correspondence should be addressed to Dr. Ariel Y. Deutch, Psychiatric Hospital at Vanderbilt, Suite 313, 1601 23rd Avenue South, Nashville, TN 37212

Copyright (C) 1998 Society for Neuroscience $\quad 0270-6474 / 98 / 1810680-08 \$ 05.00 / 0$
$\mathrm{D}_{3}$-preferring agonist 7-OH-DPAT, increased the numbers of Fos-like-immunoreactive neurons in the PVT. Conversely, the effects of cocaine and amphetamine on PVT Fos expression were blocked by pretreatment with the dopamine $D_{2 / 3}$ antagonist raclopride. Because PVT neurons express $D_{3}$ but not other dopamine receptor transcripts, it appears that psychostimulants induce Fos in PVT neurons through a $\mathrm{D}_{3}$ dopamine receptor. We suggest that the PVT may be an important part of an extended circuit subserving both the arousing properties and reinforcing aspects of psychostimulants.

Key words: amphetamine; cocaine; dopamine; D3 dopamine receptor; Fos; nucleus accumbens; thalamic paraventricular nucleus et al., 1993; Kalivas et al., 1993; Volkow et al., 1996; Wise, 1996), the lack of attention to the thalamus in the context of psychostimulants is surprising.

The paraventricular nucleus of the thalamus (PVT) is a midline nucleus that appears to be a key node in extended cortico-striatopallido-fugal circuits. The PVT receives afferents from the ventral pallidum (Haber et al., 1993; Zahm et al., 1996) and, in turn, projects to the infralimbic and prelimbic cortices in the PFC (Conde et al., 1990; Berendse and Groenewegen, 1991; Freedman and Cassell, 1994; Moga et al., 1995; Bubser and Deutch, 1998), thus completing a functional corticofugal circuit and providing entry into parallel circuits (Deutch et al., 1993; Zahm et al., 1996). The efferent projections of the PVT differ from those of the mediodorsal thalamic nucleus (which also receives ventral pallidal afferents and projects to the PFC; Groenewegen, 1988) by sending glutamatergic projections to the NAS, amygdala, and subiculum (Berendse and Groenewegen, 1990; Su and Bentivoglio, 1990; Turner and Herkenham, 1991; Moga et al., 1995; Bubser and Deutch, 1998). In addition, the PVT receives a DA innervation (Groenewegen, 1988; Takada et al., 1990; Öngür et al., 1994; Otake and Ruggiero, 1995).

We recently reported that PVT lesions block cocaine-induced locomotor sensitization, specifically disrupting the contextual conditioning of the sensitization (Young and Deutch, 1998). This observation fits well with previous studies documenting that lesions of glutamatergic projections to the NAS alter psychostimulantelicited sensitization. These behavioral data, coupled with the key anatomical placement of the PVT, led us to assess the response of PVT neurons to psychostimulants. We followed the induction of Fos, the protein product of the immediate-early gene c-fos, as a marker of PVT neurons that are metabolically activated by acute cocaine and amphetamine administration. 


\section{MATERIALS AND METHODS}

Animals and drug treatments. Adult male Sprague Dawley rats were used as subjects. Rats were group housed on a $12 \mathrm{hr}$ light/dark cycle with lights on at 6:00 A.M. Food and water were available ad libitum. To assess the effects of psychostimulants on medial thalamic Fos expression, rats were pretreated with either cocaine $(7.5,15$, or $30 \mathrm{mg} / \mathrm{kg}$, i.p.; $n=4$ per group) or D-amphetamine $(0.5,1.5$, or $5.0 \mathrm{mg} / \mathrm{kg}$, i.p.; $n=4$ per group) and killed by decapitation $2 \mathrm{hr}$ later. The PVT was dissected from two adjacent 1-mm-thick coronal slices using a punch with an outer diameter of $840 \mu \mathrm{m}$, and samples were stored at $-80^{\circ} \mathrm{C}$ until assayed by Western blots. The time course of Fos induction in the PVT in response to acute cocaine $(30 \mathrm{mg} / \mathrm{kg}$ ) was also determined; animals were administered vehicle or cocaine and killed 1,2 , or $4 \mathrm{hr}$ later ( $n=4$ per group).

We determined the regional specificity of the effects of acute cocaine (30 mg/kg, i.p.) by examining Fos expression in areas adjacent to the PVT, including the habenula, dorsal hippocampus, or mediodorsal thalamic nucleus. These regions were dissected and subsequently assayed for Fos protein levels by immunoblot procedures. In addition, regional specificity of psychostimulant-elicited Fos induction was determined using immunohistochemical methods. Rats were administered either vehicle $(n=7)$, amphetamine $(5.0 \mathrm{mg} / \mathrm{kg} ; n=9)$, or cocaine $(30 \mathrm{mg} / \mathrm{kg} ; n=$ 10) and deeply anesthetized $2 \mathrm{hr}$ later with pentobarbital. The rats were then perfused transcardially with $4 \%$ paraformaldehyde (Deutch et al., 1991).

Because amphetamine and cocaine act to increase extracellular DA levels and the PVT receives a DA innervation, we examined the response of PVT neurons to administration of DA receptor agonists. We first assessed if acute administration of the mixed $D_{1} / D_{2}$ receptor agonist apomorphine ( 0.1 and $1.0 \mathrm{mg} / \mathrm{kg} ; n=4$ for each group) alters Fos expression in PVT neurons, and then examined the effects of more selective DA agonists, including the $\mathrm{D}_{1}$ agonist SKF-38393 (2.5 and 10 $\mathrm{mg} / \mathrm{kg} ; n=3$ per group), the $\mathrm{D}_{2}$-like agonist quinpirole ( 0.1 and 1.0 $\mathrm{mg} / \mathrm{kg} ; n=4$ per group), and the $\mathrm{D}_{3}$-preferring agonist $\mathrm{R}(+) 7$-hydroxydipropylaminotetralin (7-OH-DPAT; 0.025 and $0.1 \mathrm{mg} / \mathrm{kg}, n=12$ per group). Finally, we determined if psychostimulant-elicited changes in Fos protein levels occur through increases in extracellular DA levels: rats ( $n=4$ per group) were pretreated with the $\mathrm{D}_{2 / 3}$ antagonist raclopride $(1.0 \mathrm{mg} / \mathrm{kg}$, i.p.) and $30 \mathrm{~min}$ later received either cocaine $(30 \mathrm{mg} / \mathrm{kg})$ or amphetamine $(5.0 \mathrm{mg} / \mathrm{kg})$; the rats were killed $2 \mathrm{hr}$ after psychostimulant administration.

Because $\mathrm{D}_{3}$ but not other DA receptor transcripts are present in the PVT (Mansour and Watson, 1994), we also examined the effects of 7-OH-DPAT administration on the numbers of Fos-like immunoreactive (Fos-li) neurons in the PVT, using immunohistochemical methods. Rats were subcutaneously injected with vehicle $(n=4)$ or $0.1 \mathrm{mg} / \mathrm{kg} 7-\mathrm{OH}-$ DPAT $(n=5)$, and animals were anesthetized and perfused 2 hr later.

The rewarding properties and locomotor stimulant actions of psychostimulants have been suggested to be subserved in part by the NAS. We therefore determined if amphetamine administration induced Fos in PVT neurons that project to the NAS. Rats received iontophoretic deposits of FluoroGold (FG; Fluorochrome, Englewood, CO) into the NAS through micropipettes with tip diameters of 25-30 $\mu \mathrm{m}$; FG was dissolved in $0.1 \mathrm{M}$ cacodylate and deposited by applying pulsed ( $7 \mathrm{sec}$ on/off) positive $(2.5 \mu \mathrm{A})$ current for 7-10 min. Three weeks later animals received either vehicle $(n=4)$ or amphetamine $(5.0 \mathrm{mg} / \mathrm{kg}$, i.p.; $n=6)$ and were perfused after 2 hr had elapsed. Frontal sections cut through the diencephalon and telencephalon were then processed to demonstrate retrogradely labeled cells in the PVT that expressed nuclear Fos-like immunoreactivity.

Immunoblot analyses. Fos protein levels were assessed by immunoblots of total protein isolated from tissue homogenates of brain samples. The tissue samples were sonicated in $2 \%$ SDS, and an aliquot was removed for measurement of protein levels (Lowry et al., 1951). Each lane of a $10 \%$ acrylamide $-0.27 \%$ methylenebisacrylamide gel was loaded with 50 $\mu \mathrm{g}$ of protein and run overnight at $60 \mathrm{~V}$; the protein was then transferred to nitrocellulose. The blots were incubated $4 \times 15 \mathrm{~min}$ in $2 \%$ nonfat dry milk in $\mathrm{TBS}^{+}(10 \mathrm{~mm}$ Tris, $\mathrm{pH} 7.4$, containing $150 \mathrm{~mm} \mathrm{NaCl}$ and $0.1 \%$ Tween 20) and then incubated overnight at $4^{\circ} \mathrm{C}$ in the Fos antibody (1:5000) in $\mathrm{TBS}^{+}$. The blots were washed in blocking buffer, incubated for $2 \mathrm{hr}$ in HRP-conjugated secondary antibody (Vector Laboratories, Burlingame, CA), and then washed in $\mathrm{TBS}^{+}$before being developed using enhanced chemiluminescence and exposed to Hyperfilm ECL (Amersham, Arlington Heights, IL).

Levels of Fos protein were determined using a rabbit anti-Fos antibody generated against the $\mathrm{M}$ peptide. This antibody, which recognizes Fos- related antigens (Fras) as well as Fos has been characterized previously (Quinn et al., 1989). Fos protein levels were quantitated by measuring band optical densities using computer-assisted densitometry with the public domain NIH Image program (developed at the United States National Institutes of Health and available on the Internet at http:// rsb.info.nih.gov/nih-image) after calibration using an optical step chart (Eastman Kodak, Rochester, NY). All quantitative data presented are of Fos protein and not of Fos-related antigens. In some cases, depending on the electrophoretic resolution, an apparent doublet was seen at $55 \mathrm{kDa}$; this probably represents a post-translational modification of Fos. For our densitometric evaluations of Fos, we monitored both bands together, because in all cases the two bands were similarly regulated. The optical densities were compared by means of analyses of variance followed by Bonferroni $t$ tests between comparison groups when indicated.

Immunohistochemistry. Coronal sections $(30-40 \mu \mathrm{m})$ were cut through the thalamus and forebrain on a vibrating microtome. Free-floating sections were processed immunohistochemically for the demonstration of Fos-like immunoreactivity following our previously described methods (Deutch et al., 1991). The numbers of Fos-li nuclei within the borders of the PVT were counted in sections counterstained to demonstrate tyrosine hydroxylase-immunoreactivity; the PVT can be distinguished from adjacent thalamic nuclei by the presence of a relatively dense tyrosine hydroxylase-immunoreactive axon plexus (Groenewegen, 1988; Freedman and Cassell, 1991; Bubser and Deutch, 1998). The numbers of Fos-li neurons in the PVT were compared by means of ANOVA and subsequent Tukey's tests when indicated.

To determine whether psychostimulants induce Fos in PVT neurons that project to the NAS, sections were first immunostained for Fos using nickel-cobalt-enhanced diaminobenzidine as the chromogen to reveal black Fos-li nuclei (Deutch et al., 1991). After extensive washes, sections were then processed to reveal the retrograde tracer FG using a rabbit polyclonal antibody (1:3000; Chemicon, Temecula, CA); the retrograde tracer was revealed using an immunoperoxidase procedure with diaminobenzidine as the chromogen, resulting in a brown cytosolic reaction product through which the black nuclear Fos-like immunoreactivity could be easily visualized.

\section{RESULTS}

Cocaine and amphetamine markedly increased Fos protein levels and the numbers of Fos-li neurons in the PVT. These effects were regionally specific and both dose- and time-dependent. Psychostimulant-elicited Fos induction in the PVT appeared to reflect the actions of increased extracellular DA levels. Thus, administration of $\mathrm{D}_{2}$-like DA agonists, including the $\mathrm{D}_{3}$ preferring agonist 7-OH-DPAT, increased Fos PVT expression, whereas pretreatment with the $\mathrm{D}_{2 / 3}$ antagonist raclopride blocked psychostimulant-induced PVT Fos expression.

\section{Dose-response and time course}

Acute administration of both cocaine and amphetamine dosedependently increased PVT Fos expression (Fig. 1). Both 15 and $30 \mathrm{mg} / \mathrm{kg}$ cocaine significantly increased Fos protein levels in the PVT. Amphetamine also dose-dependently increased Fos protein levels, with the 1.5 and $5.0 \mathrm{mg} / \mathrm{kg}$ doses significantly increasing levels of the protein.

Rats injected with cocaine did not show a significant increase in PVT Fos at $1 \mathrm{hr}$ after injection, but by $2 \mathrm{hr}$ there was a marked induction of the protein (Fig. 2). Fos protein levels started to subside by $4 \mathrm{hr}$ after injection, but were still significantly elevated relative to control values at this time. Because the maximal induction of Fos was seen at $2 \mathrm{hr}$ after administration, in all other experiments the animals were killed $2 \mathrm{hr}$ after drug treatment.

\section{Regional specificity}

Animals injected with $30 \mathrm{mg} / \mathrm{kg}$ cocaine or $5.0 \mathrm{mg} / \mathrm{kg}$ amphetamine showed a marked increase in Fos protein levels in the PVT when examined using immunoblots. In contrast, we were unable to detect a significant increase in Fos protein in the hippocampus or habenula of psychostimulant-treated animals (Fig. 2). No effect 

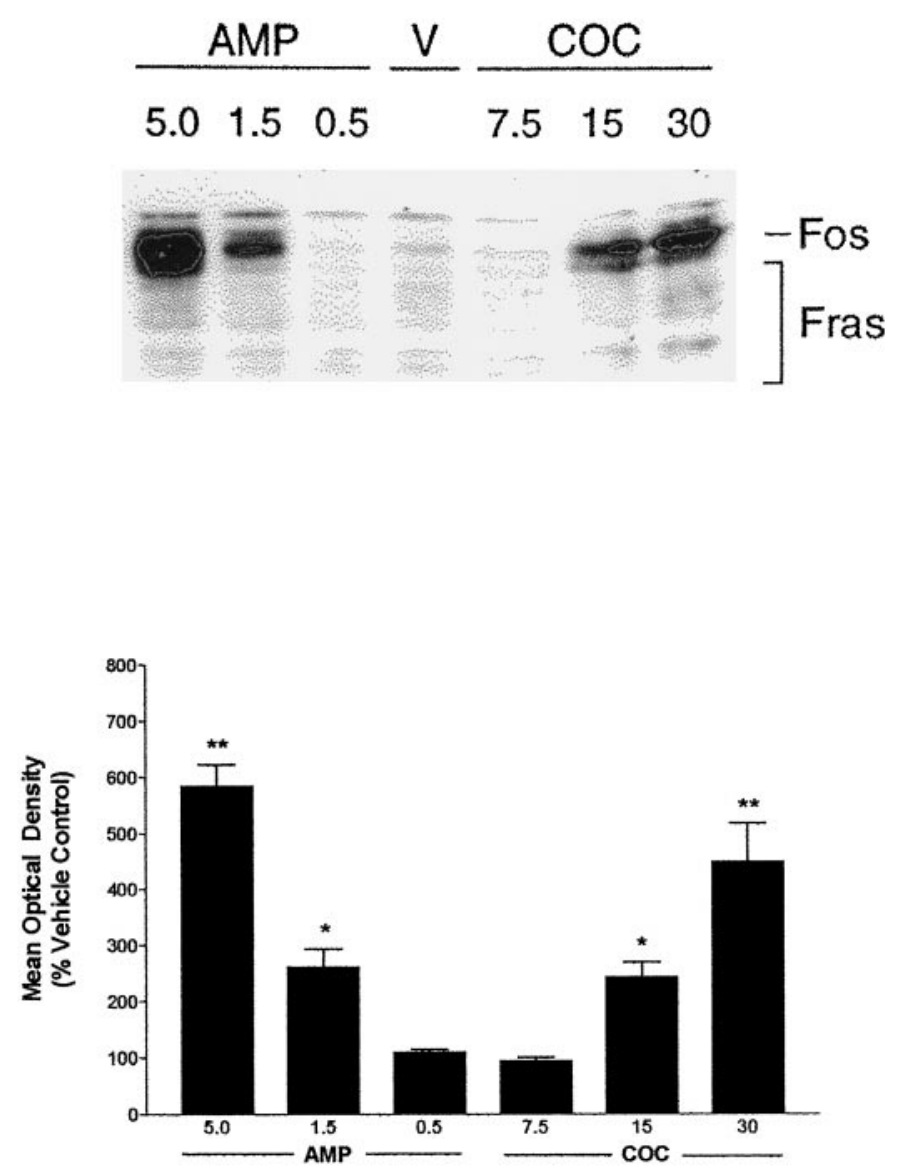

Figure 1. The effects of acute administration of cocaine $(C O C)$ and amphetamine $(A M P)$ on Fos protein levels in the PVT. A representative immunoblot is shown in the top panel, and the graphical representation of the data (expressed as percent control of vehicle) is shown in the bottom panel. Both psychostimulants dose-dependently increased PVT Fos expression. ${ }^{*} p \leq 0.05$ relative to vehicle $(V)$ control; ${ }^{* *} p \leq 0.01$ relative to vehicle control.

of cocaine or amphetamine was observed in mediodorsal thalamic nucleus (data not shown).

Immunohistochemical studies revealed that cocaine and amphetamine markedly increased the numbers of Fos-li neurons in the PVT (Fig. 3, Table 1). The effects of the psychostimulants were seen throughout the anteroposterior levels of the PVT. There were no significant differences in the magnitude of the increase in Fos-li neurons between the three anteroposterior levels of the PVT at which cell counts were made. We did not systematically count the number of Fos-li neurons in more ventral midline intralaminar nuclei, but it was our subjective impression that the two psychostimulants also increased the number of Fos-li neurons in the interanteromedial and intermediodorsal nuclei and in the central medial nucleus, albeit not to the same degree as in the PVT.

Although the effects of cocaine and amphetamine were most prominent in the PVT, a smaller but significant increase in the number of Fos-li neurons in the lateral habenula $\left(F_{(2,25)}=20.2\right.$; $p \leq 0.01)$ was also observed. The two psychostimulants did not induce Fos in the medial habenula.

\section{Effects of DA agonists and antagonists}

The mixed DA agonist apomorphine increased Fos levels in the PVT (Table 2). This effect appears to be caused by actions at
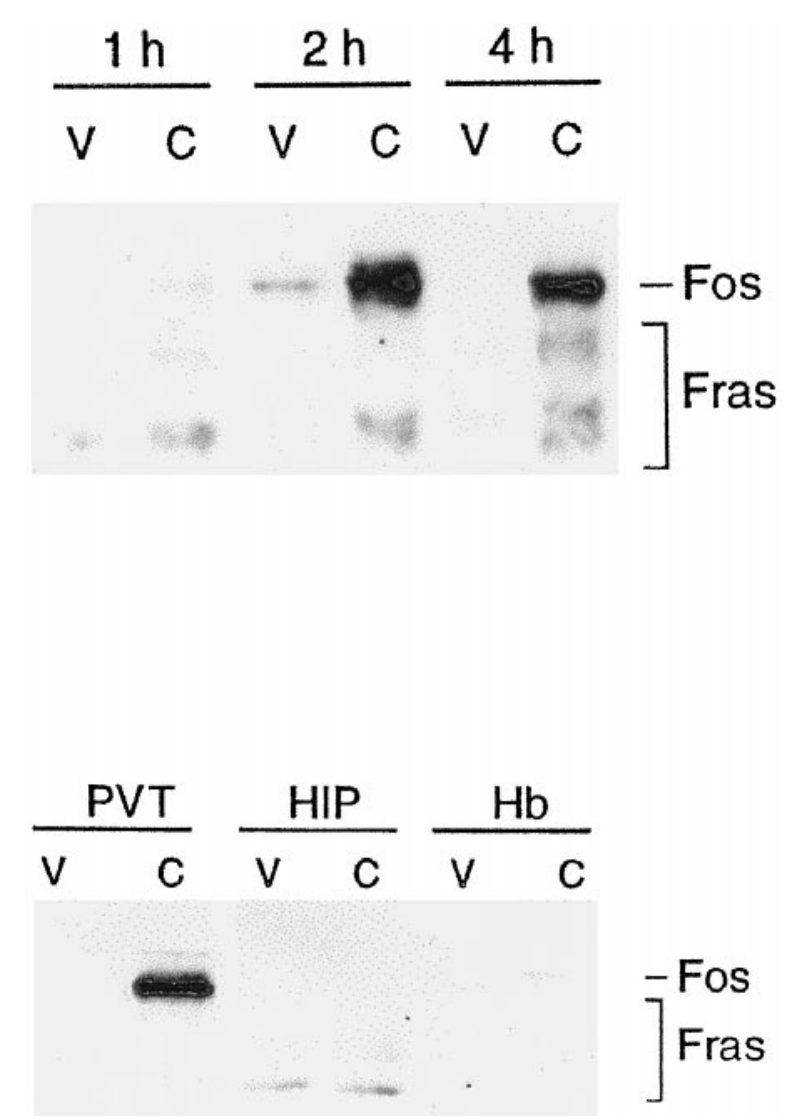

Figure 2. The top panel shows a time course of the effects of acute cocaine $(C)$ administration. Fos levels peaked at $2 \mathrm{hr}$ after cocaine injection; note that the vehicle injection resulted in a small, albeit not significant, increase in Fos expression in the PVT at $2 \mathrm{hr}$. The bottom panel shows a representative immunoblot to illustrate the regional selectivity of the effects of cocaine $(C)$ relative to vehicle $(V)$ on Fos expression. Cocaine induced Fos expression in the PVT but not the hippocampus $(H I P)$ or habenula $(H b)$.

$\mathrm{D}_{2}$-like receptors, because the $\mathrm{D}_{1}$ agonist SKF 38393 did not significantly increase PVT Fos levels $\left[F_{(2,8)}=1.51\right.$, not significant (NS)], whereas the $\mathrm{D}_{2}$-family agonist quinpirole did increase Fos expression in the PVT (Table 2).

7-OH-DPAT administration resulted in a dose-dependent increase in Fos protein levels in the PVT using immunoblot methods (Fig. 4), with the $0.1 \mathrm{mg} / \mathrm{kg}$ dose eliciting a significant increase in Fos expression. This dose is well within the range at which 7-OH-DPAT has been reported to selectively target the $\mathrm{D}_{3}$ receptor (Levant et al., 1996). In our immunoblot studies the effects of 7-OH-DPAT were somewhat variable, leading us to replicate twice the original experiment, each replication with four animals receiving vehicle and the two doses of the agonist. We therefore also examined the effects of 7-OH-DPAT using immunohistochemical methods, and again observed a significant increase in the number of Fos-li neurons in the PVT (Fig. 5). In contrast, 7-OH-DPAT treatment did not significantly increase the number of Fos-li neurons in the lateral habenula $\left(t_{(7)}=1.26, \mathrm{NS}\right)$, a site at which psychostimulants induced Fos.

Consistent with the DA agonist data, we found that pretreatment with raclopride, a $\mathrm{D}_{2 / 3}$ receptor antagonist, completely blocked the ability of cocaine to induce Fos in the PVT (Fig. 6). Raclopride itself did not significantly increase Fos levels in the PVT, consistent with our previous data (Deutch et al., 1995). We 
Anterior

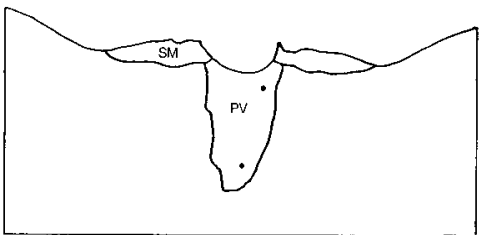

Vehicle

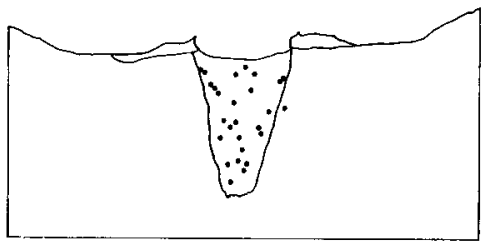

Cocaine

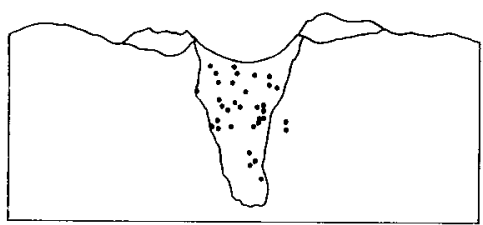

Amphetamine
Mid
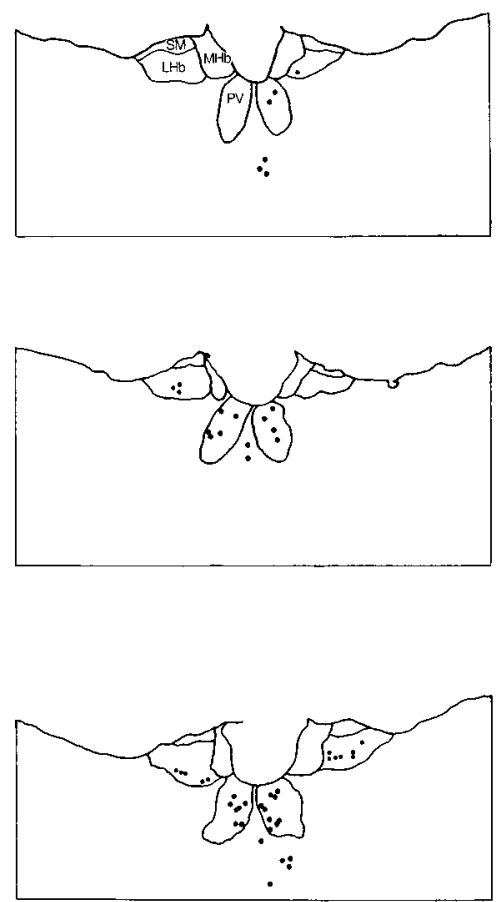

Posterior
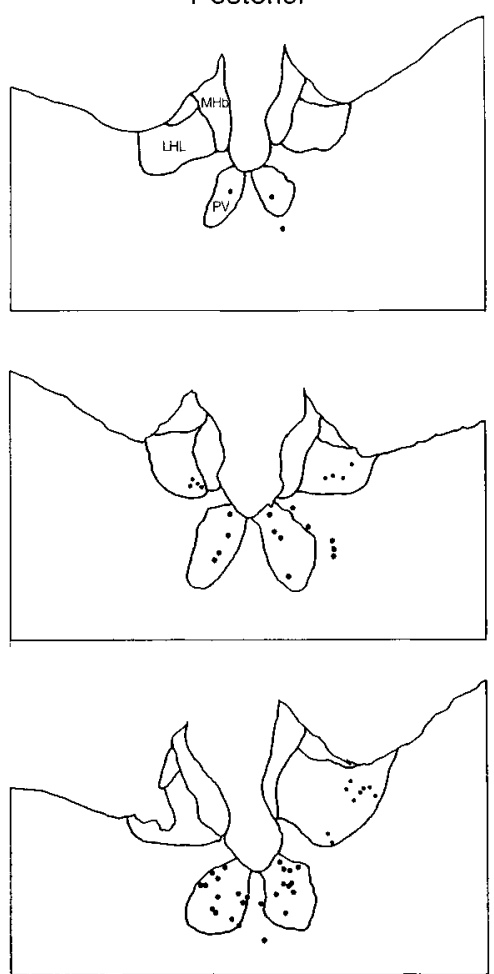

Figure 3. Charting of the distribution of Fos-li cells at three different anteroposterior levels of the PVT and in the habenula in response to acute cocaine and amphetamine injection. Each $d o t$ represents a Fos-li neuron. $L H b$, Lateral habenula; $M H b$, medial habenula; $p v$, thalamic paraventricular nucleus; $s m$, stria medullaris.

Table 1. Effects of cocaine $(30 \mathrm{mg} / \mathrm{kg})$ or amphetamine $(5.0 \mathrm{mg} / \mathrm{kg})$ on the numbers of Fos-li neurons in the thalamic paraventricular nucleus

\begin{tabular}{llcl} 
& PVA & PV & PVP \\
\hline Vehicle (7) & $16.4 \pm 3.8$ & $8.3 \pm 1.9$ & $10.1 \pm 2.8$ \\
Cocaine (10) & $42.8 \pm 4.0^{*}$ & $28.6 \pm 2.5^{*}$ & $33.1 \pm 6.6^{* *}$ \\
Amphetamine (9) & $42.6 \pm 6.2^{*}$ & $31.6 \pm 3.3^{*}$ & $46.8 \pm 6.2^{*}$
\end{tabular}

Data are presented as the mean ( \pm SEM) number of Fos-li neurons in the anterior (PVA), central (PV), or posterior (PVP) PVT.

${ }^{*} p \leq 0.01 ;{ }^{*} p \leq 0.05$.

also found that raclopride pretreatment blocked amphetamineelicited PVT Fos expression (data not shown).

\section{The nucleus accumbens as a target of PVT neurons that express Fos}

Deposits of the retrograde tracer FG involved primarily the shell and septal pole compartments of the NAS (Fig. 7) and resulted in extensive labeling of cells in the PVT. Although few retrogradely labeled PVT neurons expressed Fos-like immunoreactivity in vehicle-treated rats, administration of amphetamine increased the number of retrogradely labeled PVT neurons with Fos-li nuclei (Fig. 7). In our limited sample, 5.7\% of PVT neurons that were retrogradely labeled from the NAS in vehicle-treated rats expressed Fos-like immunoreactivity. In contrast, $16.0 \%$ of retrogradely labeled neurons expressed Fos-like immunoreactivity in amphetamine-treated animals. The effect of amphetamine appeared to be more pronounced in the anterior PVT: $5.4 \%$ of the retrogradely labeled cells were Fos-li in vehicle-treated rats, whereas $22.6 \%$ of the retrogradely labeled anterior PVT neurons expressed Fos-li nuclei in amphetamine-injected rats.

\section{DISCUSSION \\ Technical issues}

We used Fos as a reporter system to reveal the effects of acute psychostimulant administration on PVT neurons. It is difficult to monitor changes in PVT DA release using ex vivo biochemical methods, because the dense noradrenergic innervation of the PVT clouds interpretation of the source of DA metabolites (Scatton et al., 1984); in vivo methods are similarly constrained because the small size of the PVT precludes microdialysis studies. Fos has been used widely and with considerable success as a marker of neurons that are functionally activated by various stimuli, but there are certain limitations to the method. The cell population of interest must be capable of mounting a Fos response; this obviously holds true for PVT neurons. Under basal conditions Fos is expressed solely in neurons (Mugnaini et al., 1989), but under toxic conditions (such as trauma or ischemia) Fos can be expressed in glia as well as neurons. We observed Fos-like immunoreactivity in neurons, including those that project to the NAS. A possible concern is that high doses of cocaine can cause seizures, which dramatically induce Fos in certain sites, including the hippocampus. We did not find any effect of acute cocaine (30 $\mathrm{mg} / \mathrm{kg}$ ) on hippocampal Fos expression, nor does amphetamine result in seizures at the doses used.

Immunoblot procedures are a useful means of exploring the pharmacological substrates of psychostimulant-elicited Fos expression and allow for the specific monitoring of Fos protein expression. We did not routinely measure levels of Fras, but it was 
Table 2. The effects of dopamine agonists on Fos protein expression in the PVT

\begin{tabular}{|c|c|c|c|c|c|c|}
\hline \multirow[b]{2}{*}{ Vehicle } & \multicolumn{2}{|c|}{ Apomorphine } & \multicolumn{2}{|l|}{ Quinpirole } & \multicolumn{2}{|l|}{ SKF 38393} \\
\hline & $0.1 \mathrm{mg} / \mathrm{kg}$ & $0.5 \mathrm{mg} / \mathrm{kg}$ & $0.1 \mathrm{mg} / \mathrm{kg}$ & $0.5 \mathrm{mg} / \mathrm{kg}$ & $2.5 \mathrm{mg} / \mathrm{kg}$ & $10 \mathrm{mg} / \mathrm{kg}$ \\
\hline $100 \pm 18$ & $266 \pm 23^{*}$ & $359 \pm 48^{* *}$ & $358 \pm 77$ & $475 \pm 141^{*}$ & $154 \pm 48$ & $232 \pm 18$ \\
\hline
\end{tabular}

Data are shown as the mean $( \pm$ SEM) optical density values expressed as a percent of vehicle control. The sample size for all groups is 4 . ${ }^{*} p \leq 0.05 ; * * p \leq 0.01$.

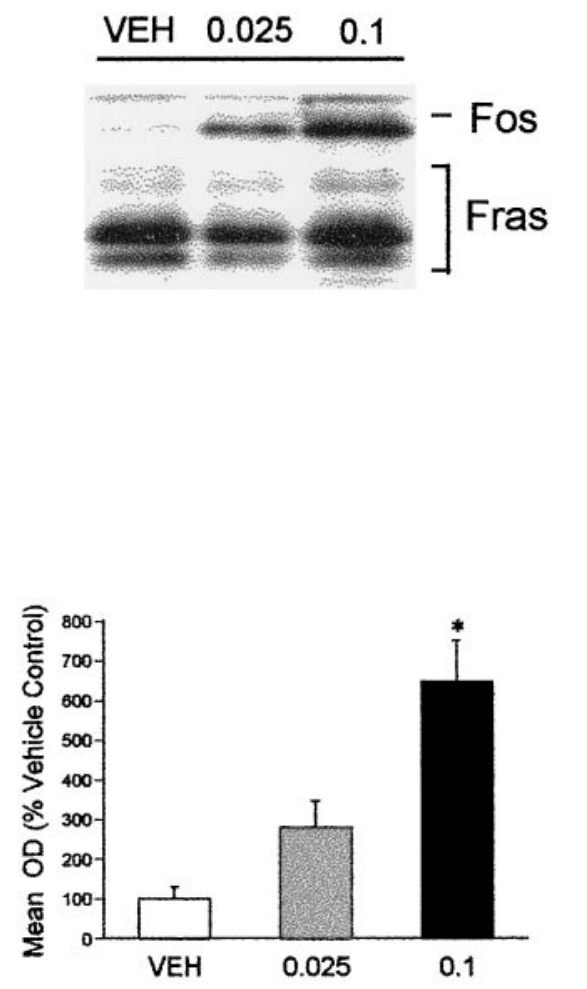

Figure 4. The effects of acute administration of the $\mathrm{D}_{3}$-preferring agonist 7-OH-DPAT on Fos protein levels in the PVT. The top panel shows an immunoblot demonstrating the effects of 7-OH-DPAT on Fos protein levels, with the lower panel showing the graphical representation of the PVT Fos response across all animals. The higher $(0.1 \mathrm{mg} / \mathrm{kg})$ dose of the agonist significantly increased Fos expression. ${ }^{*} p \leq 0.05$ relative to vehicle-injected control.

our subjective impression that several Fras were also induced by psychostimulant treatment. Immunoblot methods lack the spatial localization afforded by immunohistochemical methods. In most cases our anatomical and immunoblot studies corresponded well, clearly indicting that cocaine and amphetamine induce Fos in PVT neurons. Moreover, our anatomical data are consistent with the report of Brown et al. (1992), who noted that acute cocaine administration increases the number of Fos-li PVT neurons. There was, however, one region where we obtained discrepant results using immunoblot and immunohistochemical approaches. Immunoblot studies did not reveal any significant effects of psychostimulants on the lateral habenula, but anatomical studies showed a significant increase in the number of Fos-li neurons in the lateral (but not medial) habenula. This latter finding agrees with the report of Wirtshafter et al. (1994), who noted that amphetamine increased Fos-li neurons in the lateral habenula. Our habenula dissection for immunoblot studies included both lateral and medial habenula. Because the latter site did not respond to psychostimulants with an increased number of Fos-li

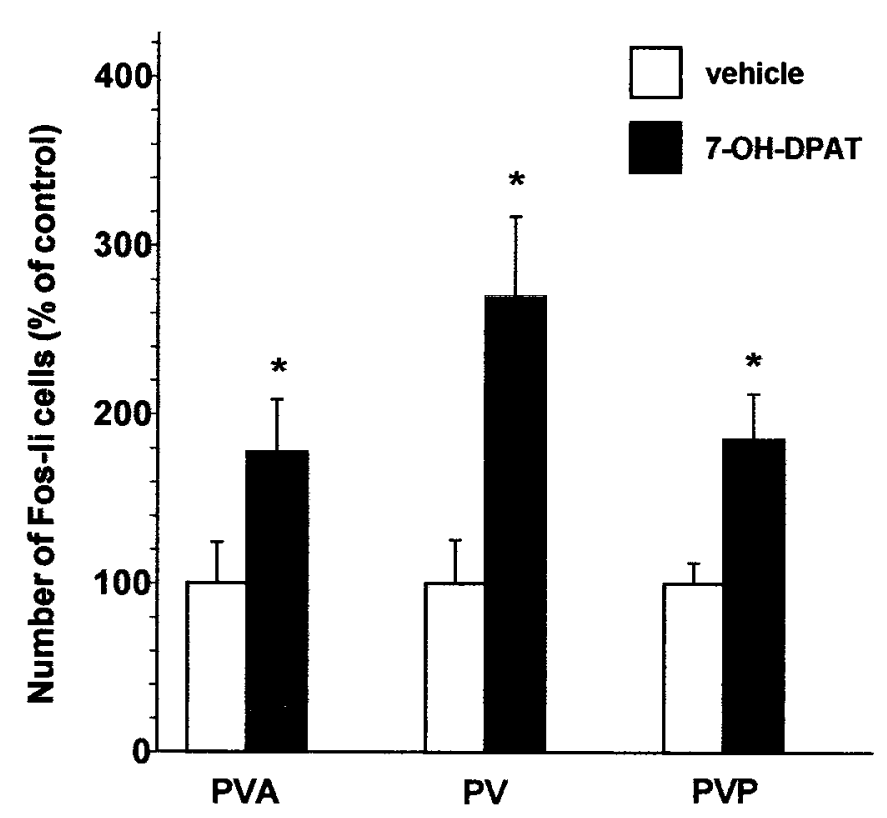

Figure 5. The effects of $0.1 \mathrm{mg} / \mathrm{kg}$ 7-OH-DPAT on the numbers of Fos-li neurons in the PVT. The $\mathrm{D}_{3}$-preferring agonist significantly increased the numbers of Fos-li PVT neurons at all anteroposterior levels. ${ }^{*} p \leq 0.05$.

neurons, the dissection of the habenula may have limited the ability of the immunoblot procedure to detect changes in Fos restricted to the lateral habenula.

\section{Dopaminergic substrates of psychostimulant-elicited PVT Fos expression}

Many actions of psychostimulants are mediated by DA. There is a relatively dense plexus of DA-immunoreactive fibers in the PVT, which falls off sharply at the border of the PVT with the medial segment of the mediodorsal thalamic nucleus (Groenewegen, 1988; Freedman and Cassell, 1991). The PVT receives DA afferents from hypothalamic DA neurons and midbrain DA neurons (Otake and Ruggiero, 1995; Takada et al., 1990; our unpublished observations), and PVT neurons express $\mathrm{D}_{3}$ receptor mRNA (Mansour and Watson, 1994) and $\mathrm{D}_{3}$-binding sites (Levant et al., 1993). Finally, the DA transporter has been reported to be present in the midline thalamic nuclei (Fujita et al., 1994).

Accordingly, dopaminergic mechanisms may subserve psychostimulant-elicited Fos expression in the PVT. However, cocaine and amphetamine increase extracellular levels of norepinephrine as well as DA, and cocaine significantly increases extracellular serotonin (Lin et al., 1996; Parsons et al., 1996). The PVT receives relatively dense norepinephrine, epinephrine, and serotonin innervations (Lindvall et al., 1974; Bosler et al., 1987; Freedman and Cassell, 1991; Otake and Ruggiero, 1995). To determine whether the effects of psychostimulants on PVT Fos involved increased extracellular DA levels, we examined the ability of DA agonists to mimic the effects of psychostimulants on 

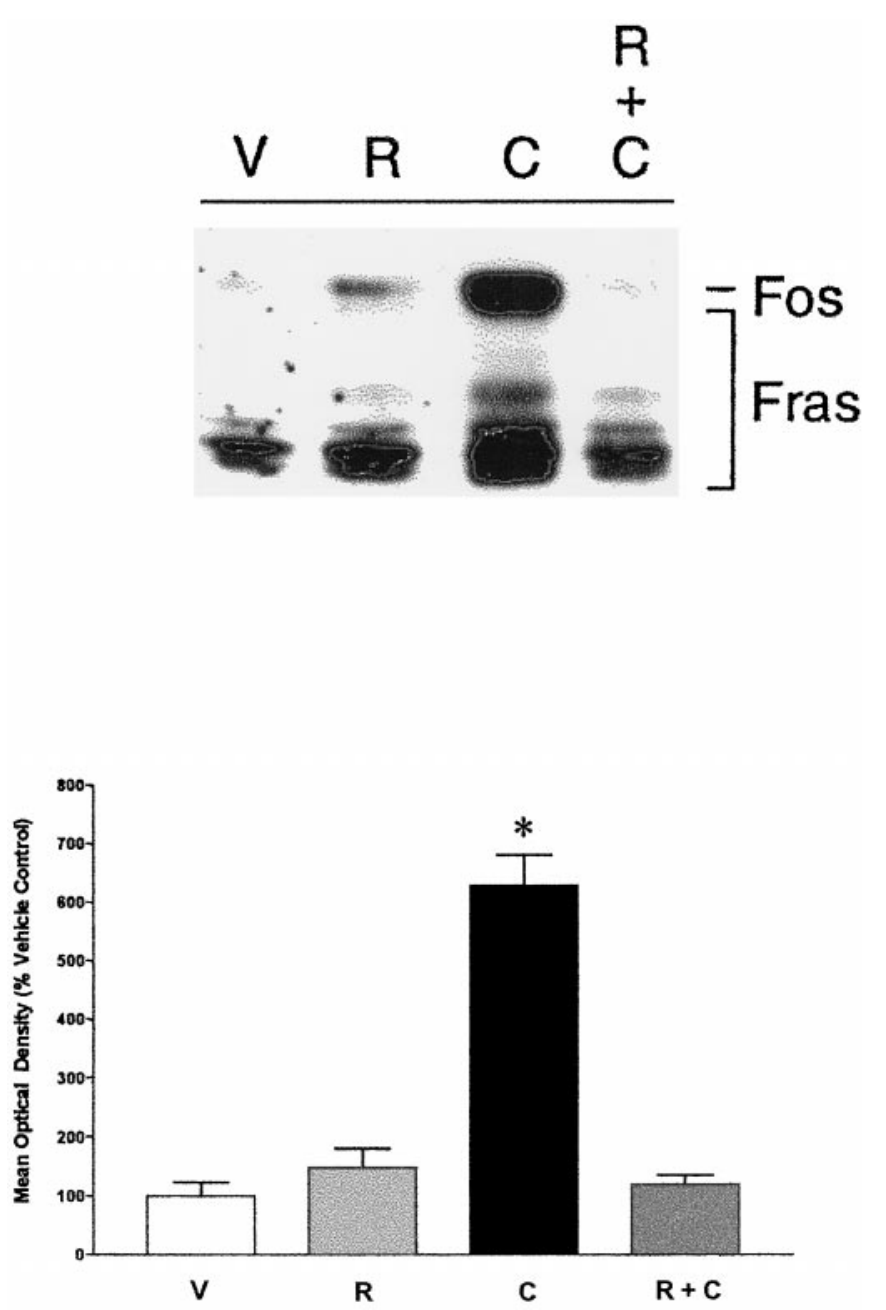

Figure 6. The effects of DA receptor antagonist pretreatment on cocaine-elicited Fos induction. Pretreatment with the $D_{2 / 3}$ antagonist raclopride $(R)$, which did not significantly change Fos expression by itself, blocked the ability of cocaine $(C)$ to induce Fos in the PVT $(R+C) .{ }^{*} p \leq$ 0.01 relative to vehicle control

PVT Fos expression and of a DA antagonist to block psychostimulant-elicited Fos induction in the PVT.

The mixed $\mathrm{D}_{1 / 2}$ agonist apomorphine increased Fos expression in the PVT. Similar effects were seen after pretreatment with the $\mathrm{D}_{2}$-like agonist quinpirole, but not in response to the $\mathrm{D}_{1}$ agonist SKF 38393. Moreover, 7-OH-DPAT, at a dose that selectively interacts with $\mathrm{D}_{3}$ receptors (Levant et al., 1996), increased PVT Fos expression. These data agree well with the expression of the $\mathrm{D}_{3}$ but not other DA receptors in PVT neurons (Mansour and Watson, 1996). Finally, the $\mathrm{D}_{2 / 3}$ receptor antagonist raclopride completely blocked the ability of cocaine and amphetamine to induce Fos protein in the PVT. Because raclopride has no significant affinity for adrenergic or serotonergic receptors, it appears that the effects of psychostimulants on PVT Fos are predominantly subserved by dopaminergic mechanisms. It remains to be determined which of the many behavioral and physiological effects of psychostimulants are reflected by the induction of Fos protein in the PVT.

Because PVT neurons express the $\mathrm{D}_{3}$ but not other DA receptors (Mansour and Watson, 1994), it follows that DA-mediated psychostimulant actions in the medial thalamus either occur through $\mathrm{D}_{3}$ receptors expressed on PVT neurons or indirectly

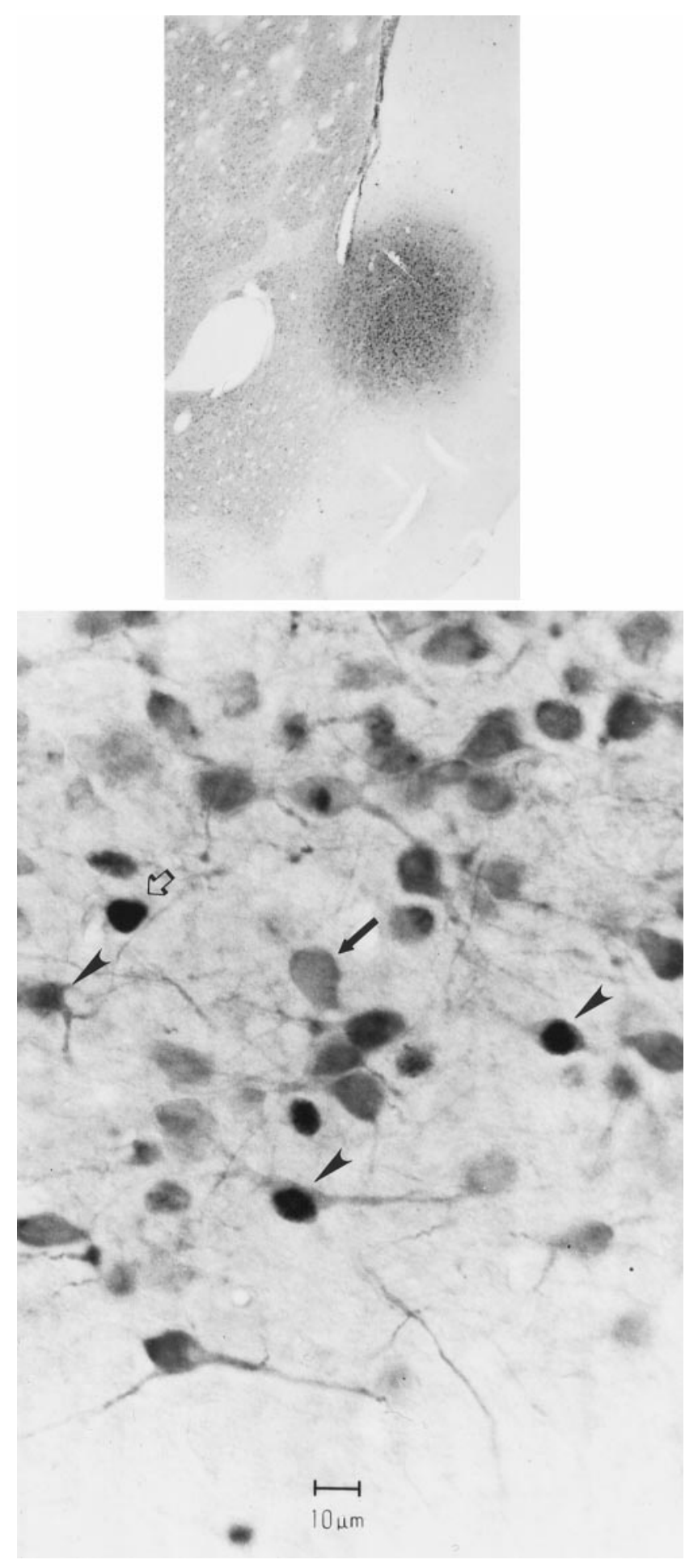

Figure 7. The bottom panel is a photomicrograph of PVT neurons retrogradely (FluoroGold) labeled from the nucleus accumbens (diffuse cytoplasmic labeling, arrows), some of which express Fos-li nuclei (arrowheads). Other Fos-li neurons that are not retrogradely labeled (open arrows) are also visible. This photomicrograph was taken from an animal that received $5.0 \mathrm{mg} / \mathrm{kg}$ D-amphetamine, with the FluoroGold injection site into the septal pole/shell of the nucleus accumbens (top panel).

through transsynaptic activation of the PVT. We cannot distinguish between these two possibilities at this point.

Koob and associates have argued that $\mathrm{D}_{3}$ DA receptors are critical to the rewarding properties of psychostimulants (Caine 
and Koob, 1993; Parsons et al., 1996; Caine et al., 1997). 7-OHDPAT, the $\mathrm{D}_{3}$-preferring agonist, substitutes fully for an amphetamine-discriminative stimulus at doses that target $\mathrm{D}_{3}$ but not $\mathrm{D}_{2}$ receptors (Bevins et al., 1997) and $\mathrm{D}_{3}$ agonists also generalize to cocaine (Acri et al., 1995; Lamas et al., 1996). Moreover, an increase in the density of $\mathrm{D}_{3}$ receptors has been reported in post mortem studies of chronic cocaine abusers (Staley and Mash, 1996). Although most speculation on the involvement of $\mathrm{D}_{3}$ receptors in psychostimulant actions has been in the context of $\mathrm{D}_{3}$ receptors localized to accumbal neurons, it is possible that the reinforcing effects of drugs of abuse also involve $\mathrm{D}_{3}$ sites present on accumbal afferents (Rodriquez De Fonseca et al., 1995), such as those from the PVT.

\section{Functional considerations}

The PVT is anatomically positioned to influence forebrain sites involved in psychostimulant actions, including the NAS, PFC, and amygdala. We found that acute psychostimulant administration resulted in an increase in Fos expression in neurons that were retrogradely labeled from the NAS. We did not determine whether PVT neurons that project to other sites are also impacted by psychostimulant administration, choosing to focus on the NAS first because of the large body of data relating accumbal function to psychostimulants. Indeed, because many Fos-li neurons present in the PVT after amphetamine administration are not retrogradely labeled from the NAS, it is likely that psychostimulants may drive PVT influences over several forebrain sites, including such regions as the PFC and amygdala.

Although the precise roles that the PVT may play in psychostimulant actions remain to be established, there are two possible functions on which we can speculate. Although the PVT and related intralaminar nuclei have been classically considered to represent "nonspecific" thalamic relays for ascending reticular formation neurons, these nuclei are very specific in their cortical projections (Berendse and Groenewegen, 1991) and may exert greater specific regulatory influences over certain cortical (and subcortical) targets than hitherto realized (Groenewegen and Berendse, 1994). The PVT projects strongly to several mesocorticolimbic DA terminal fields. Single cholinergic reticular formation neurons collateralize to innervate both the PVT and ventral tegmental area (Bolton et al., 1993), thus providing a means by which reticular core information can directly (through the VTA) and indirectly (via PVT projections to the NAS, PFC, and amygdala) regulate forebrain DA function. This suggests that the PVT may be important as a generalized arousal relay to mesolimbic DA terminal fields, including the NAS, PFC, and AMG. In addition, in view of recent data suggesting that pontine cholinergic reticular formation neurons are involved in the rewarding effects of opiates (Olmstead et al., 1998), and because these neurons are a primary source of afferents to the PVT, the PVT may subserve the rewarding properties of psychostimulants and other drugs of abuse.

We have recently reported that PVT lesions block the conditioned aspects of cocaine-induced behavioral sensitization (Young and Deutch, 1998). In contrast, Pierce et al. (1998) reported that PVT lesions do not disrupt expression of cocaineelicited sensitization; however, their lesions spared the anterior half of the PVT and they did not assess the effects of lesions on the conditioned component of sensitization. Our lesion data are consistent with those of Brown et al. (1992), who noted that although Fos is induced in many central sites of rats injected acutely with cocaine, the PVT was among the few regions in which Fos was induced in animals exposed to a neutral stimulus previously paired with cocaine. These data suggest that the PVT may be important in associating the rewarding aspects of psychostimulants with contextual cues, and, thus, may be relevant to the craving that psychostimulant abusers report when confronted with secondary reinforcers.

\section{REFERENCES}

Acri JB, Carter SR, Alling K, Geter-Douglass B, Dijkstra D, Wikstrom H, Katz JL, Witkin JM (1995) Assessment of cocaine-like discriminative stimulus effects of dopamine $\mathrm{D}_{3}$ receptor ligands. Eur J Pharmacol 260:177-181.

Berendse HW, Groenewegen HJ (1990) Organization of the thalamostriatal projections in the rat, with special emphasis on the ventral striatum. J Comp Neurol 299:187-228.

Berendse HW, Groenewegen HJ (1991) Restricted cortical termination fields of the midline and intralaminar nuclei in the rat. Neurosci 42:73-102.

Bevins RA, Klebaur JE, Bardo MT (1997) 7-OH-DPAT has D-amphetamine-like discriminative stimulus properties. Pharmacol Biochem Behav 58:485-490.

Bolton RF, Cornwall J, Phillipson OT (1993) Collateral axons of cholinergic pontine neurones projecting to midline, mediodorsal and parafascicular thalamic nuclei in the rat. J Chem Neuroanat 6:101-114.

Bosler O, Beaudet A, Denoroy L (1987) Electron-microscopic characterization of adrenergic axon terminals in the diencephalon of the rat. Cell Tissue Res 248:393.

Brown EE, Robertson GS, Fibiger HC (1992) Evidence for conditioned neuronal activation following exposure to a cocaine-paired environment: role of forebrain limbic structures. J Neurosci 12:4112-21.

Bubser M, Deutch AY (1998) Thalamic paraventricular nucleus neurons collateralize to innervate the prefrontal cortex and nucleus accumbens. Brain Res 787:304-310.

Burns LH, Robbins TW, Everitt BJ (1993) Differential effects of excitotoxic lesions of the basolateral amygdala, ventral subiculum and medial prefrontal cortex on responding with conditioned reinforcement and locomotor activity potentiated by intra-accumbens infusions of D-amphetamine. Behav Brain Res 55:167-183.

Caine SB, Koob GF (1993) Modulation of cocaine self-administration in the rat through D-3 dopamine receptors. Science 260:1814-1816.

Caine SB, Koob GF, Parsons LH, Everitt BJ, Schwartz JC, Sokoloff P (1997) D3 receptor test in vitro predicts decreased cocaine selfadministration in rats. NeuroReport 8:2373-2377.

Christie MJ, Summers RJ, Stephenson JA, Cook CJ, Beart PM (1987) Excitatory amino acid projections to the nucleus accumbens septi in the rat: a retrograde transport study utilizing $\mathrm{D}\left[{ }^{3} \mathrm{H}\right]$ aspartate and $\left[{ }^{3} \mathrm{H}\right]$ GABA. Neuroscience 22:425-439.

Conde F, Audinat E, Maire-Lepoivre E, Crepel F (1990) Afferent connections of the medial frontal cortex of the rat. A study using retrograde transport of fluorescent dyes. I. Thalamic afferents. Brain Res Bull 24:341-34.

Deutch AY, Lee MC, Gillham MH, Cameron D, Goldstein M, Iadarola MJ (1991) Stress selectively increases Fos protein in dopamine neurons innervating the prefrontal cortex. Cereb Cortex 1:273-292.

Deutch AY, Bourdelais AJ, Zahm DS (1993) The nucleus accumbens core and shell: accumbal compartments and their functional attributes. In: Limbic motor circuit and neuropsychiatry (Kalivas PW, Barnes CD, eds), pp 45-88. Boca Raton, FL: CRC.

Deutch AY, Öngür D, Duman RS (1995) Fos induction by antipsychotic drugs in the medial thalamus: a novel locus of antipsychotic drug action. Neuroscience 66:337-346.

Di Chiara G, Imperato A (1988) Drugs abused by humans preferentially increase synaptic dopamine concentrations in the mesolimbic system of freely moving rats. Proc Natl Acad Sci USA 85:5274-5278.

Freedman LJ, Cassell MD (1991) Thalamic afferents of the rat infralimbic and lateral agranular cortices. Brain Res Bull 26:957-964.

Fujita M, Shimada S, Fukuchi K, Tohyama M, Nishimura T (1994) Distribution of cocaine recognition sites in rat brain: in vitro and ex vivo autoradiography with [125]RTI-55. J Chem Neuroanat 7:13-23.

Fuller TA, Russchen FT, Price JL (1987) Sources of presumptive glutamatergic/aspartergic afferents to the rat ventral striatopallidal region. J Comp Neurol 258:317-338.

Groenewegen HJ (1988) Organization of the afferent connections of the 
mediodorsal thalamic nucleus in the rat, related to the mediodorsalprefrontal topography. Neuroscience 24:379-431.

Groenewegen HJ, Berendse HW (1994) The specificity of the "nonspecific" midline and intralaminar thalamic nuclei. Trends Neurosci 17:52-57.

Groenewegen HJ, Berendse HW, Wolters JG, Lohman AHM (1990) The anatomical relationship of the prefrontal cortex with the striatopallidal system, the thalamus, and the amygdala: evidence for a parallel organization. Prog Brain Res 85:95-118.

Haber SN, Lund-Balta E, Mitchell SJ (1993) The organization of the descending ventral pallidal projections in the monkey. J Comp Neurol 329:111-128.

Kalivas PW (1995) Interactions between dopamine and excitatory amino acids in behavioral sensitization to psychostimulants. Drug Alcohol Depend 37:95-100.

Kalivas PW, Stewart J (1991) Dopamine transmission in the initiation and expression of drug- and stress-induced sensitization of locomotor activity. Brain Res Rev 16:223-244.

Kalivas PW, Churchill L, Klitenick MA (1993) The circuitry mediating the translation of motivational stimuli into adaptive motor responses. In: Limbic motor circuits and neuropsychiatry (Kalivas PW, Barnes CD, eds), pp 237-287. Boca Raton, FL: CRC.

Lamas X, Negus SS, Nader MA, Mello NK (1996) Effects of the putative dopamine $\mathrm{D}_{3}$ receptor agonist 7-OH-DPAT in rhesus monkeys trained to discriminate cocaine from saline. Psychopharmacology $124: 306-314$.

Levant B, Grigoriadis DE, DeSouza EB (1993) $\left[{ }^{3} \mathrm{H}\right]$ Quinpirole binding to putative $\mathrm{D}_{2}$ and $\mathrm{D}_{3}$ dopamine receptors in rat brain and pituitary gland: a quantitative autoradiographic study. J Pharmacol Exp Ther 264:991-1001.

Levant B, Bancroft GN, Selkirk CM (1996) In vivo occupancy of D2 dopamine receptors by 7-OH-DPAT. Synapse 24:60-64.

Lin MY, Yam QS, Coffey LL, Reith ME (1996) Extracellular dopamine, norepinephrine, and serotonin in the nucleus accumbens of freely-moving rats during intracerebral dialysis with cocaine and other monoamine uptake blockers. J Neurochem 66:559-568.

Lindvall O, Bjorklund A, Nobin A, Stenevi U (1974) The adrenergic innervation of the rat thalamus as revealed by the glyoxylic acid fluorescence method. J Comp Neurol 154:317-348.

Lowry OH, Rosebrough NJ, Farr AL, Randall RJ (1951) Protein measurement with the Folin phenol reagent. J Biol Chem 193:265-275.

Mansour A, Watson SJ (1995) Dopamine receptor expression in the CNS. In: Psychopharmacology: the fourth generation of progress (Bloom F, Kupfer D, eds), pp 207-219. New York: Raven.

McGinty JF (1995) Introduction to the role of excitatory amino acids in the actions of abused drugs. Drug Alcohol Depend 37:91-94.

Moga MM, Weis RP, Moore RY (1995) Efferent projections of the paraventricular nucleus thalamic nucleus in the rat. J Comp Neurol 359:221-238.

Mugnaini E, Berrebi AS, Morgan JI, Curran T (1989) Fos-like immunoreactivity induced by seizure in mice specifically associated with euchromatin in neurons. Eur J Neurosci 1:46-52.

Olmstead MC, Munn EM, Franklin KBJ, Wise RA (1998) Effects of pedunculopontine tegmental nucleus lesions on responding for intravenous heroin under different schedules of reinforcement. J Neurosci 18:5035-5044.

Öngür D, Duman RS, Deutch AY (1994) Pharmacological characterization of the dopamine innervation of the thalamic paraventricular nucleus. Soc Neurosci Abstr 20:530.

Otake I, Ruggiero DA (1995) Monoamines and nitric oxide are employed by afferents engaged in midline thalamic regulation. J Neurosci 15:1891-1911.
Parsons LH, Koob GF, Weiss F (1996) Extracellular serotonin is decreased in the nucleus accumbens during withdrawal from cocaine self-administration. Behav Brain Res 73:225-228.

Pierce RC, Reeder DC, Hicks J, Morgan ZR, Kalivas PW (1998) Ibotenic acid lesions of the dorsal prefrontal cortex disrupt the expression of behavioral sensitization to cocaine. Neurosci 82:1103-1114.

Post RM, Weiss SRB, Pert A (1988) Cocaine-induced behavioral sensitization and kindling: implications for the emergence of psychopathology and seizures. Ann NY Acad Sci 537:292-308.

Quinn JP, Takimoto M, Iadarola MJ, Holbrook N, Levens D (1989) Distinct factors bind the AP-1 consensus sites in gibbon ape leukemia virus and simian virus 40 enhancers. J Virol 63:1737-1742.

Robbins TW, Everitt BJ (1996) Neurobehavioral mechanisms of reward and motivation. Curr Opin Neurobiol 6:228-236.

Rodriguez de Fonseca F, Rubio P, Martin-Calderon JL, Caine SB, Koob GF, Navarro M (1995) The dopamine receptor agonist 7-OH-DPAT modulates the acquisition and expression of morphine-induced place preference. Eur J Pharmacol 274:47-55.

Scatton B, Dennis T, Curet O (1984) Increase in dopamine and DOPAC levels in noradrenergic terminals after electrical stimulation of the ascending noradrenergic pathways. Brain Res 298:193-196.

Staley JK, Mash DC (1996) Adaptive increase in D3 dopamine receptors in the brain reward circuits of human cocaine fatalities. J Neurosci 16:6100-6106.

Su H-S, Bentivoglio M (1990) Thalamic midline cell populations projecting to the nucleus accumbens, amygdala, and hippocampus in the rat. J Comp Neurol 297:582-593.

Swerdlow NR, Koob GF (1987) Dopamine, schizophrenia, mania, and depression: toward a unified hypothesis of cortico-striato-pallidothalamic function. Behav Brain Sci 10:197-245.

Takada M, Campbell KJ, Moriizumi T, Hattori T (1990) On the origin of the dopaminergic innervation of the paraventricular thalamic nucleus. Neurosci Lett 115:33-36.

Turner BH, Herkenham M (1991) Thalamoamygdaloid projections in the rat: a test of the amygdala's role in sensory processing. J Comp Neurol 313:295-325.

Volkow ND, Ding YS, Fowler JS, Wang GJ (1996) Cocaine addition: hypothesis derived from imaging studies with PET. J Addict Dis 15:55-71.

Wirtschafter D, Asin KE, Pitzer MR (1994) Dopamine agonists and produce different patterns of Fos-like immunoreactivity in the lateral habenula. Brain Res 633:21-26.

Wise RA (1994) Cocaine reward and cocaine craving: the role of dopamine in perspective. NIDA Res Monogr 145:191-206.

Wise RA (1996) Neurobiology of addiction. Curr Opin Neurobiol 6:243-251.

Wolf ME (1998) The role of excitatory amino acids in behavioral sensitization to psychomotor stimulants. Prog Neurobiol 54:679-720.

Wolf ME, Dahlin SL, Hu XT, Xue CJ, White K (1995) Effects of lesions of prefrontal cortex, amygdala, or fornix on behavioral sensitization to amphetamine: comparison with $N$-methyl-D-aspartate antagonists. Neuroscience 69:417-439.

Yoshikawa T, Shibuya H, Kaneno S, Toru M (1991) Blockade of behavioral sensitization to methamphetamine by lesion of hippocampalaccumbal pathway. Life Sci 48:1325-1332.

Young CD, Deutch AY (1998) The effects of thalamic paraventricular nucleus lesions on cocaine-induced locomotor activity and sensitization. Pharmacol Biochem Behav 60:753-758.

Zahm DS, Williams E, Wohtmann C (1996) Ventral striatopallidothalamic projection: IV. Relative involvements of neurochemically distinct subterritories in the ventral pallidum and adjacent parts of the rostroventral forebrain. J Comp Neurol 364:340-362. 